\title{
New Structuralism and the Balance-of-Payments Constraint
}

\author{
Gabriel Porcile \\ Economic Affairs Officer, ECLAC and UFPR (Brazil) \\ Giuliano Toshiro Yajima \\ Ph.D. candidate, Sapienza University of Rome (Italy)
}

\begin{abstract}
Structuralists and Post-Keynesians share the perspective that in the long run economic growth is shaped by the income elasticity of exports and imports, and that such elasticities are a positive function of the degree of diversification and technological intensity of the pattern of specialization. Since the mid-seventies, New Structuralists began to stress the role of two set of variables in driving the pattern of specialization: a stable and competitive real exchange rate, and the relative intensity of innovation / diffusion of technology in center and periphery. In this paper we modify the Balance-of-Payments constrained growth model to include these two set of variables. The model provides a mechanism that ensures the validity of the original Thirlwall's perspective, namely that adjustment to the Balance-of-Payments-constrained equilibrium takes place through changes in the rate of growth of aggregate demand rather than through changes in relative prices. In addition, it shows that a macroeconomic policy aimed at sustaining a competitive real exchange rate is a necessary complement to an active industrial policy for fostering international convergence.
\end{abstract}

Keywords: BOP-constrained growth models, Technological innovation, Structural Change

JEL classifications: F43, O40, 041 


\section{New Structuralism and the Balance-of-Payments Constraint}

\section{Motivation}

This paper discusses the Balance of Payments-constrained growth model from the perspective of the Structuralist tradition. The central tenet of Structuralism is that the dynamics of innovation and diffusion of technology creates different production structures and learning dynamics that tend to reproduce or even amplify initial asymmetries in technological and productive capabilities (the technology gap and the pattern of specialization, respectively). If market forces are left alone, the result is a center-periphery dynamic that carries crucial implications for growth and income distribution. Such a dynamic can be observed across regions within a country and across countries at an international level.

Since the mid-seventies, new debates emerged in Latin America expanding the original Structuralist ideas on economic development. These new theoretical insights gave rise to what would be labelled "New Structuralism" in the late eighties (Rodríguez, 2006, chapter 11), which benefited from the cross-fertilization between the "old" Structuralism and advances in the theory of technological change, structural change, inflation and the importance of the real exchange rate for economic growth. The new structuralism began as a response to increasing difficulties faced by the Latin American countries to sustain its industrialization process, along with the macroeconomic instability that haunted the region in the late seventies and eighties. Initially, it sought to understand the specific challenges faced by the region in this period (Fajnzylber, 1990). Gradually, new structuralist ideas became part of a broader intellectual tradition discussing the specific problems faced by open economies in an international system marked by strong technological and financial asymmetries (Ffrench-Davis and Ocampo, 2001). In this process, new structuralist benefited from both new theoretical insights and empirical evidence.

In the theoretical realm, there are strong connections between the New Structuralism, the Schumpeterian and the Keynesian schools of thought on growth and distribution. The key link between New Structuralism and the Keynesian traditions is the assertion (shared by the original center-periphery model and the Keynesian growth models for open economies) that the external constraint limits the ability of the periphery to raise its rate of growth and converge in income per capita with the developed economies (Rodríguez, 2006; Cimoli et al, 2013). The external 
constraint is expressed in the ratio between the income elasticity of exports and the income elasticity of imports (Thirlwall's Law in its simplest version - see Dixon and Thirlwall, 1975). In turn, the key link between the New Structuralist tradition and the Schumpeterian tradition is the claim that the income elasticity ratio is rooted in different patterns of specialization in center and periphery, which vary in response to the co-evolution structural and technological change (Verspagen, 1993; Faberberg and Verspagen, 2002).

Empirical studies were also important as source of inspiration for revisiting structuralist ideas. In particular, the comparison between the industrialization path and policies in Latin America and the Asian economies was critical for understanding the role played in convergence by two sets of policy variables: industrial and technological policies that encourage economic diversification towards more technology-intensive sectors; macroeconomic policies sustaining a stable and competitive real exchange rate-with its implications for managing the capital account and devising macroprudential policies (Ocampo et al, 2009). Important policy lessons came from Asia that had to be absorbed by structuralists studying Latin America.

The paper is organized in 6 sections. Section 2 briefly reviews the empirical literature on the impact of the technology gap and the real exchange rate (RER) on structural change and growth. Section 3 presents the basic equations and the short run equilibrium in a Thirlwall-Dutt model based on Dutt (2002). This model is modified and expanded to explore New Structuralist ideas in section 4, based on the empirical evidence of section 2. Section 5 focuses on comparative dynamics in the medium run and in the long run. In the medium run the technology gap is given, but the RER and the investment rate may vary. In the long run the technology gap varies. Section 6 concludes.

2. Technology, export diversification and the RER: a review of the empirical evidence

The idea that there is a positive association between technological capabilities and the degree of diversification and sophistication of exports finds extensive empirical support in the literature. For a comprehensive review of the technology-specialization link see Fagerberg et al (2001), Fagerberg and Verspagen (2002), Cimoli and Katz (2003), Felipe et al (2012) and Bogliacino and Pianta (2016). On the other hand, the role of the RER in fostering changes in the pattern of specialization has been less consensual at both the empirical and theoretical level. We 
will focus mainly on reviewing the empirical contributions, while the theoretical aspects of this relationship are explored in the following sections. We argue that by large the literature support that the RER can have a significant impact on the pattern of specialization. This result is important for the New Structuralist view of the determinants of growth and will be used extensively in our modified Thirlwall-Dutt Model presented below.

The pioneer work is Baldwin (1988), who suggests that the RER may produce "hysteresis in trade", i.e. there is a permanent effect on exports of a temporary change in the RER. By running a structural break regression of the log of the real exchange rate on the log of import prices for the US in the period 1967-1987, he observes that large and persisting appreciations of the RER in the eighties lowered the pass-through from RER to import prices. He gives as an explanation the fact that foreign competitors have to pay the sunk costs required to access the US domestic market. As those costs cannot be recovered, once these firms enters the US market they prefer to squeeze their profit margins by applying a lower pass-through rather than to exit the market. The decline of the pass-through in import prices following a period of appreciation is also confirmed for Japan by Otani et al. (2003, 2006).

Mcmillan and Rodrick (2011) and Diao et al. (2017) define structural change as the residual from the decomposition of productivity growth in a "within" and a "structural" component. Using the 10-sector database of the Groningen Growth and Development Center (GGDC), they reported a positive and statistically significant effect on the structural component in a panel of 39 countries covering the 1950-2015 period. Mbaye (2013), in a panel of 72 countries over the period 19702008 observes that depreciation has a higher impact on the growth of total factor productivity than on capital accumulation. Thus result is by large explained by a "pure composition effect" - i.e. production reallocation from the non-tradables to the tradables sectors. Rodrick (2008) argues that currency undervaluation helps to overcome market and institutional failures that compromise the expansion of the tradable sector. His econometric exercise identifies a larger effect of depreciation on countries that present below-average institutional quality, signaling the possibility of using devaluation as a second-best policy for structural change in developing economies.

Another stream of literature addresses structural change in terms of an increase in the extensive margin, i.e. the diversification of exported products. Freund and Pierola (2008, 2012) argue that a large depreciation of the RER allows developing countries to open up new lines of exports, and hence they can benefit more from an undervalued currency. A similar argument is put 
forward by Elbadawi et al (2009), who provide evidence that overvaluations had a negative impact on export diversification for 83 Sub-Saharian countries in the period 1970 to 2004. Colacelli (2010) and Goya $(2014,2018)$ find out that the impact of the RER on export diversification happens mainly through the variety channel (the increase in the number of different products exported), rather than through the concentration channel. They observe that not only the level of the RER, but also RER volatility, affect export diversification, especially in the case of diversification towards more sophisticated goods. The effect of a higher RER may also be driven by processes of import substitution. ${ }^{1}$

Caglayan and Demir (2019) take into account differences in both skill content and the direction of trade in assessing the impact of the RER on exports. They provide evidence of RER affecting positively medium and low skill manufactures, while high-skill ones and primary goods are less responsive. Cimoli et al (2013), working with a panel of 111 countries for the period 19612008, find out that the RER has a significant impact on the technological intensity of exports after controlling for the level of the GDP per capita. At variance with the previous results, Agosin et al (2011), working with a dataset of 79 countries, do not find an effect of the RER level, although they identify a negative impact of RER volatility on export diversification ${ }^{2}$.

Within the Post-Keyensian tradition, and in particular in the framework of Thirwall's Law, the price and income elasticities of export and imports are considered to depend on the country's pattern of specialization. Gouvea and Lima (2010) show empirical evidence of how elasticities vary as a result of changes in export patterns, although they do not discuss to what extent such changes respond to the RER. Cimoli et al (2010), Bresser-Pereira (2016) and Bresser-Pereira et al (2014) have suggested that the ratio between the income elasticities of exports and imports may vary as a result of the RER and hysteresis effects. Bresser-Pereira et al (2014) argue that this ratio varies as a function of the difference between the observed and the industrial equilibrium $\mathrm{RER}^{3}$. Marconi et al (2015) have tested this hypothesis for a panel of 65 countries between 1995 and 2012, finding out a positive association between this distance and the income elasticity ratio, a result that is robust to the introduction of several control variables (such as the share of

\footnotetext{
${ }^{1}$ Moreira et al. (2017) has shown that in Latin America for the period 2008-2014 a 1\% increase in the RER led to a reduction in import penetration on average by $0,41 \%$ to $0,69 \%$.

${ }^{2}$ For the New-Structuralists, the RER should be both competitive and stable. See on this point Ffrench-Davis and Ocampo (2001), Ocampo et al (2009), Ffrench-Davis (2012) and Guzmán et al (2018).

${ }^{3}$ The industrial equilibrium RER is defined by Bresser-Pereira (2016) as the one that makes competitive those industrial firms that are using state-of-the art technology.
} 
manufacturing in GDP, the current account balance as a percentage of GDP, and the growth rate of the export of manufactured goods). The importance of the RER for growth and the income elasticities ratio is confirmed by Missio et al (2015) for a broad sample of 103 countries between 1978 and 2007 and by Nassif et al $(2015,2018)$ working with Brazilian data in the period 19802010. Gala (2008) highlights the differences in the management of the RER between East Asian and Latin American economies to explain the contrasting growth performance of the two regions since the '90s. According to Razmi et al (2012), the channel through which an undervalued RER can stimulate output growth is to be found in the investment demand that stimulates, in particular, the tradable sector. Libman et al (2019) demonstrate in a panel of 184 countries for 1950-2014 that episodes of sustained capital accumulation lead to a shift from agriculture to manufacturing sectors and cause the trade balance to follow a U-shaped pattern - following an initial deterioration due to increased imports and then recovering afterwards as the export sector gain competitiveness. A combination of a competitive RER with active industrial policies has been observed in most of the successful cases of catching up and convergence (Cimoli et al, 2019).

Some Post-Keynesian scholars contend that the development effects of the exchange rate should be qualified in some cases. Blecker and Razmi (2008) observe that RER devaluations in developing countries do help to increase their growth rate, but at the expense of growth in other countries at a similar level of development. Ibarra and Blecker (2016), in their estimate of the Balance-of-Payments-constrained rate of growth of Mexico, find out small effects of the RER on exports due to the high share of imported intermediate inputs in the total cost of Mexican exporters. Although these authors do not dismiss the hypothesis of a developmental channel for a competitive RER level, they show that its effects may be limited in certain cases which are relevant for developing economies.

All in all, a competitive RER contributes to export diversification and hysteresis phenomena may be at work, making diversification a persistent, rather than a temporary, outcome. As the export structure varies - driven by the extensive margin — so does the ratio between the income elasticities of exports and imports. This effect may be small in some cases, especially when exports are intensive in imported inputs. Moreover, the historical experience of Asia and Latin America suggests that - in the successful cases of convergence-managing the RER to upgrade the export structure has gone hand in hand with active industrial and technological policies (Ocampo et al, 2009; Cimoli et al, 2013). 
3. $\quad$ A modified Dutt-Thirwall model: basic equations and short-run equilibrium

This section takes as a point of departure the model set forth by Dutt (2002) and propose three modifications to this model. The first modification is to relate the dynamics of the RER to mark-up pricing; the second modification is to include the determinants of the pattern of specialization in the model, based on the literature reviewed in the previous section; the third modification is to make changes in capitalists' expectations a function of the trade balance. These modifications allow us to suggest a Robinsonian interpretation of the adjustment mechanism to external disequilibrium - through changes in investment decisions (see Robinson, 1966) rather than through changes in the terms of trade. We argue that these modifications are consistent with the insights of Thirlwall's Law and the Structuralist tradition.

Prices in center and periphery are set based on a mark-up rule as stated in equations (1) and (2), respectively:

$$
\begin{aligned}
& P_{N}=(1+f) W_{N} b_{N} \\
& P_{S}=(1+z) W_{S} b_{S}
\end{aligned}
$$

The subscripts $N$ and $S$ represent North and South, or center and periphery, respectively; $P_{S}$ is the price of the good produced in the periphery, $P_{N}$ the price of the good produced in the center, $f$ is the mark-up in the center, $z$ is the mark-up in the periphery, $W_{N}$ and $W_{S}$ are nominal wages and $b_{N}$ and $b_{S}$ are labor coefficients (labor per unit of output). Define the profit share as $\sigma=(P Y-W L) / P Y$, then using the price equation (2) and the technical coefficient of labor in the periphery, $b_{S}=L_{S} / Y_{S}$, it is possible to find the profit share in the periphery:

(3) $\sigma_{S}=1-\frac{W L}{P Y}=\frac{z}{(1+z)}$

The static condition for external equilibrium is:

$$
P_{S} X=P_{N} E M
$$


In equation (4) $E$ is the nominal exchange rate (price of the foreign currency in units of the domestic currency), which will be assumed constant and equal to 1 . Define the real exchange rate as $q=P_{N} / P_{S}$. Exports from the periphery are represented by the following equations:

$$
X_{S}=\theta_{S} q^{\mu_{N}} Y_{N}^{\varepsilon_{N(q, G)}}
$$

$$
\theta_{S}=\frac{\alpha_{0}\left[1+\left(1-s_{N}\right) f\right]}{1+f}
$$

Where $\theta_{S}$ is the share of goods imported from the periphery in the consumption of the center, $f$ is the mark-up in the center, $s_{N}$ the savings rate of the capitalists in the center (it is assumed that workers do not save), $\sigma_{N}=f /(1+f)$ is the profit share in total income, $\omega_{N}=$ $1 /(1+f)$ is the wage share, $\alpha_{0}$ is a constant, $\mu_{N}$ is the price elasticity of imports and $\varepsilon_{N}(q, G)$ the income elasticity of imports of the center. Based on the review of the literature in section 2, we claim that the income elasticity of imports (exports) of the center (periphery) is a function of the technological gap $G$ and the RER in the periphery. The lower the technology gap (the higher the technological capabilities of the periphery as compared to those of the center) and the higher the RER, the more diversified and the more technology-intensive the pattern of specialization of the periphery will be.

The demand of imports from the periphery (which equals exports from the center) is:

$$
X_{N}=\theta_{N} q^{-\mu_{S}} Y_{S}^{\varepsilon_{S}}
$$

In the periphery, workers only consume domestic goods, while capitalists save and invest all their profits in both domestic and foreign goods:

$$
\theta_{N}=\beta_{0} \sigma_{S}
$$

As shown in equation (3), $\sigma_{S}=z /(1+z)$ is the profit share in total income in the periphery and $\beta_{0}$ is a constant and $\theta_{N}$ is the share of imported foreign capital goods in total investment in the periphery. The wage share is $\omega_{S}=1 /(1+z)$. 
In equations (6) and (9), $\theta_{S}$ and $\theta_{N}$ are constants. By using equations (5) and (7) and logdifferentiating equation (4) with respect to time, it is possible to find the dynamic condition for external equilibrium:

$$
g_{S}^{*}=\left(\frac{\varepsilon_{N(q, G)}}{\varepsilon_{S}}\right) g_{N}+\frac{\left(\mu_{N}+\mu_{S}-1\right)}{\varepsilon_{S}} \hat{q}
$$

where $\hat{q}=\widehat{P_{N}}-\widehat{P_{S}}$ and $g_{i=N, S}$ represents proportional rate of growth $(g \equiv \dot{Y} / Y)$. The rate of growth of the center is an exogenous constant $g_{N}$ for the periphery (the periphery is a small country). Marshall-Lerner holds and hence $\mu_{N}+\mu_{S}>1$. While equation (9) gives the rate of growth of the periphery consistent with the external constraint $\left(g_{S}^{*}\right)$, the effective rate of growth depends on the capitalists' decisions over capital accumulation. At variance with Dutt's model, capitalists in the South follow a conventional Kaleckian investment function (Badhuri and Marglin, 1990):

$$
g_{S}=\gamma_{0}+\gamma_{1} u+\gamma_{2} \sigma_{S}
$$

In equation (10) $u$ is the rate of utilization of the stock of capital in the periphery $(Y / \bar{Y})$, where $\bar{Y}=v K$ is the income of the periphery when the capital stock is used at full capacity and $v$ is capital productivity. The parameter $\gamma_{0}$ represents the animal spirit (driven by expectations about future growth in the periphery), $\gamma_{1}$ is the response to changes in the degree of capital utilization (which reflects the desire of the capitalists of keeping a certain level of unused capacity to respond to competitive threats under imperfect competition), and $\gamma_{2}$ gives the response of investment to the profit share in total income. All parameters are positive. Recall the that capitalists save all profits which implies $g_{S}=(I / K)=(S / K)=\sigma_{S}(Y / K)=\sigma_{S} u v$. To save notation, normalize $v=$ 1. The short run equilibrium is given by:

$$
u=\frac{\gamma_{0}+\gamma_{2} \sigma_{S}}{\sigma_{S}-\gamma_{1}}
$$

The usual condition for a stable equilibrium $\left(\sigma_{S}>\gamma_{1}\right)$ applies. Plugging (11) in (10) gives the effective rate of capital accumulation: 


$$
g_{S}=\gamma_{0}+\gamma_{1}\left(\frac{\gamma_{0}+\gamma_{2} \sigma_{S}}{\sigma_{S}-\gamma_{1}}\right)+\gamma_{2} \sigma_{S}
$$

The economic growth regime is profit-led (wage-led) if a rise in $\sigma_{S}$ increases (reduces) $g_{S}$. Taking the derivative with respect to the profit share in equation (13) renders

$$
\frac{\partial g_{S}}{\partial \sigma_{S}}=\frac{\gamma_{2}-u}{\gamma_{2}-\gamma_{1}}
$$

The signal of this derivative, positive or negative, defines whether the growth regime is profit-led or wage-led, respectively.

From equations (4), (5) and (7) it is possible to find the RER that ensures external equilibrium:

$$
q=\left[\frac{\theta_{N}}{\theta_{S}} \frac{\left(Y_{S}\right)^{\varepsilon} S}{\left(Y_{N}\right)^{\varepsilon_{N}(q, G)}}\right]^{1 /\left(\mu_{S}+\mu_{N}-1\right)}
$$

This is the static condition for external equilibrium. In the following sections we will allow RER and investments to vary in the medium-run, and the technology gap to vary in the long run.

4. The dynamic system: the RER, the animal spirit and the technology gap

The dynamic condition of equilibrium in the trade balance stated in equation (9) can be rearranged as follows:

$$
\hat{q}=\left[1 /\left(\mu_{S}+\mu_{N}-1\right)\right]\left(\varepsilon_{S} g_{S}-\varepsilon_{N(q, G)} g_{N}\right)
$$

In the medium-run the technology gap is constant, but the RER varies. Based on Blecker (2012) and Lima and Porcile (2013), we assume a variable mark-up. Firms set a target for the profit share in total income and adjust the mark-up to attain this target: 


$$
\hat{z}=\vartheta\left(\sigma_{S}^{f}-\sigma_{S}(z)\right)=\vartheta\left(\frac{z^{f}}{\left(1+z^{f}\right)}-\frac{z}{(1+z)}\right)
$$

In equation (16), $z^{f}$ is the mark-up aimed at by firms. The parameter $\vartheta$ is the speed of adjustment of the observed profit share to the profit share desired by the capitalists. If the observed profit share is lower than the desired profit share, they will raise their mark ups to attain the desired profit share. The value of $z^{f}$ depends on the monopoly power of the firms, and hence on the degree of openness of the economy, regulations, price elasticity and barriers to entry in the different markets for the goods produced in the periphery, factors considered exogenous to the model. It also depends on the power of labor unions to transform productivity growth into higher real wages.

To keep the model tractable, we assume that wages increase hand in hand with labor productivity, and therefore $\widehat{w_{S}}=-\widehat{b_{S}}$. Using this result in the price equation (2) gives $\widehat{P_{S}}=-\widehat{Z}$ (see also Lima and Porcile, 2014). Recalling that $\widehat{q}=\widehat{P_{N}}-\widehat{P_{S}}$ and setting (with no loss of generality) $\widehat{P_{N}}=0$, then $\hat{q}=-\widehat{P_{s}}=-\hat{z}$. The rise in prices makes domestic inflation overcome international inflation; as a result, the domestic good becomes more expensive than the foreign goods as compared with the initial situation, bringing the RER down. Equation (16) produce an equilibrium value for the RER which decreases monotonically with the mark-up $z^{f}$ and the desired profit share $\sigma_{S}^{f}$ aimed at by the firms. In equilibrium, when $z=z^{f}$, firms do not have motives to change the mark-up and (with the assumption that $\widehat{w_{S}}=-\widehat{b_{S}}$ ), both domestic inflation and foreign inflation are equal to zero.

If the RER is determined in the labor market, which variable is doing the heavy lifting to lead the economy to its external equilibrium (zero net exports)? If relative prices no longer do the trick, it is necessary to specify a mechanism that ensures that the equality $\varepsilon_{N} g_{N}=\varepsilon_{S} g_{S}$ holds (for a comparison between the adjustment process in the modified model and the one suggested in Dutt (2002), see Appendix I at the end of the paper). We suggest a Robinsonian twist in the canonical Kaleckian investment function as the key adjustment mechanism. Joan Robinson argued that the role of an external surplus (deficit) is to boost (depress) the animal spirit of the capitalists. A surplus in the trade balance is a signal that growth will continue without being threatened by an external crisis, a sharp depreciation of the currency or a sudden stop in foreign credit. In the words of Joan Robinson $(1966$, p.): 
"the most important benefit of a surplus on income account, which affects the whole economy, is that, provided that there are energetic enterprises and thrifty capitalist to take advantage of it, it permits home investments to go full steam while a deficit country is nervously pulling on the brake for fear of excessive imports".

To formalize this idea, we make the animal spirit (represented by $\gamma_{0}$, the "autonomous" component of the investment function) a monotonically increasing function of the trade balance. The animal spirit diminishes with a trade deficit and is stirred by a trade surplus. Formally, this means that the animal spirit increases when the rate of economic growth with external equilibrium, given by equation (9), exceeds the effective rate of growth given by equation (12):

$$
\widehat{\gamma_{0}}=\varphi(\underbrace{\left(\frac{\varepsilon_{N}(q, G)}{\varepsilon_{S}}\right) g_{N}+\frac{\left(\mu_{N}+\mu_{S}-1\right)}{\varepsilon_{S}} \vartheta\left(\sigma_{S}(z)-\sigma_{S}^{f}\right)}_{g_{S}^{*}}-
$$

$\underbrace{\gamma_{0}-\gamma_{1}\left(\frac{\gamma_{0}+\gamma_{2}\left(\sigma_{S}(z)\right)}{\left(\sigma_{S}(z)\right)-\gamma_{1}}\right)-\gamma_{2}\left(\sigma_{S}(z)\right)}_{g_{S}})$

The differential equations (16) and (17) form a dynamic system with state variables $\gamma_{0}$ and $z$ (the real exchange rate and the animal spirit are the two state variables).

$$
J=\left|\begin{array}{ll}
\partial \hat{z} / \partial z & \partial \hat{z} / \partial \widehat{\gamma_{0}} \\
\partial \widehat{\gamma_{0}} / \partial z & \partial \widehat{\gamma_{0}} / \partial \gamma_{0}
\end{array}\right|=\left|\begin{array}{cc}
- & 0 \\
? & -
\end{array}\right|
$$

The trace of the Jacobian is negative and the determinant positive. Hence the system is unambiguously stable, even though the sign of $\partial \widehat{\gamma_{0}} / \partial z$ is not well defined. Taking the derivative of equation (17) with respect to $z$ gives:

\footnotetext{
${ }^{4}$ The term "autonomous" makes reference to the fact that this component of the investment function does not respond directly to changes in income levels. However, it is no longer an exogenous parameter but a a function of the trade balance in equation (17).
} 


$$
\frac{\widehat{\partial \gamma}_{0}}{\partial z}=\varphi\left(\left(\frac{g_{N}}{\varepsilon_{S}}\right) \frac{\partial \varepsilon_{N}}{\partial q} \frac{\partial q}{\partial z}+\frac{\left(\mu_{N}+\mu_{S}-1\right)}{\varepsilon_{S}} \vartheta\left(\frac{\partial \sigma_{S}}{\partial z}\right)-\gamma_{1}\left(\frac{\left(\frac{\partial \sigma_{S}}{\partial z}\right)\left[\gamma_{2} \sigma_{S}(z)-\gamma_{2} \gamma_{1}-\left(\gamma_{0}+\gamma_{2} \sigma_{S}(z)\right)\right]}{\left(\sigma_{S}(z)-\gamma_{1}\right)^{2}}\right)-\right.
$$

$\left.\gamma_{2}\left(\frac{\partial \sigma_{S}}{\partial z}\right)\right)$

The first term on the right-hand-side of equation (19) is negative because a rise in $z$ reduces the real exchange rate and this curbs diversification and the income elasticity of exports of the periphery; the second term is positive because a rise in $z$ reduces the distance between the desired and the effective profit share, and hence the rate of growth of the mark-up and the inflation rate (assuming an initial condition $z^{f}>z$ ); the third and fourth terms combined $\left(\partial g^{s} / \partial z\right)$ will be negative if the economy is profit-led, and positive if the economy is wage-led.

\section{Comparative dynamics: the impact of changes in competitiveness and global growth}

\section{The profit-led economy}

We first address the medium run, when the technology gap is given (technology changes occur at a slower pace than investment decisions and change in prices). Assume initially that the economy is profit-led. Assume, in addition, that the price elasticities of exports and imports are not very high, i.e. $\left(\mu_{N}+\mu_{S}-1\right) \cong 0$, and hence we can neglect the second term on the righthand-side of equation (20). If the economy is profit-led, then the derivative (19) will be unambiguously negative and the isocline $\widehat{\gamma_{0}}=0$ downward sloping. This means that lower levels of autonomous expenditure are required to keep zero net exports when the mark-up is high (and competitiveness is low). Figure 1 shows the phase diagram and the equilibrium values of the markup $\left(z^{f}\right)$ and of "autonomous" investment $\left(\gamma_{0}^{e}\right)$. 
Figure 1. Growth, profit shares and competitiveness in the medium run and in the long run

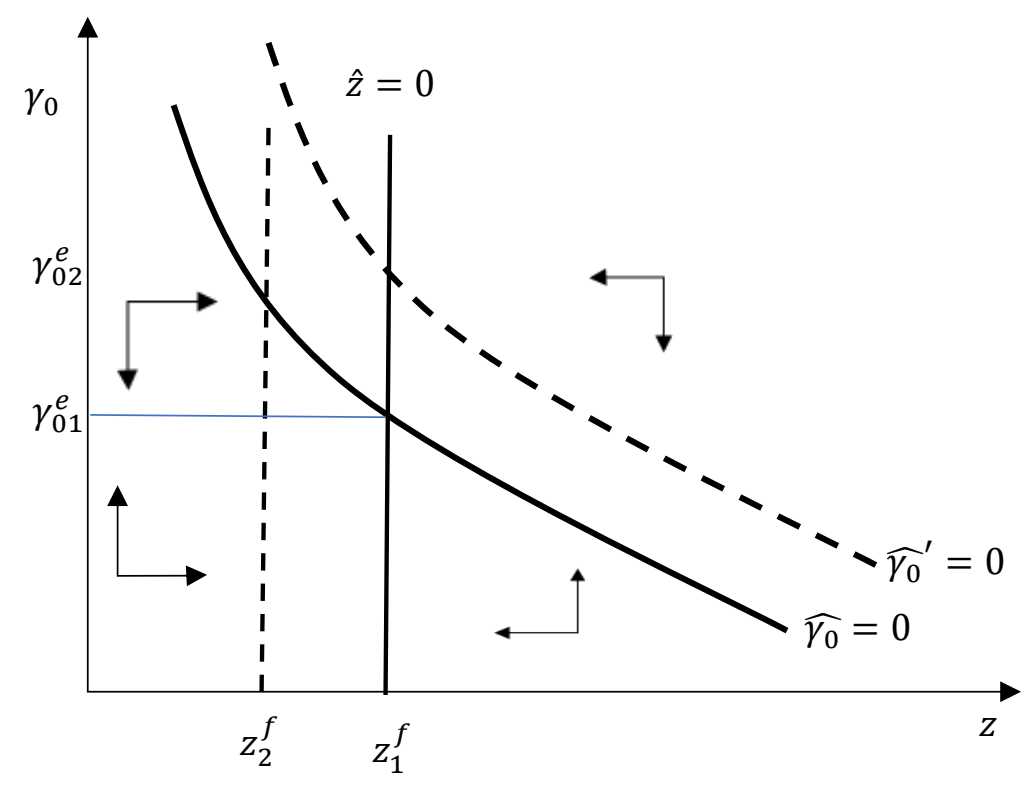

The dynamics represented in figure 1 offers several interesting insights. Assume that the monopoly power of firms in the periphery falls, which makes the capitalists accept a lower profit share as a target (moving the $\hat{z}=0$ isocline to the left, from say the vertical line $z_{1}^{f}$ to $z_{2}^{f}$ ). This move may arise out of a process of opening the economy to trade or adopting regulations that enhance competition in the domestic market or allow unions to capture a higher share of total income for given prices, curbing the market power of the capitalists. Since by assumption the economy is profit-led, a fall in the desired mark-up reduces the effective rate of growth $g_{S}$. However, at the same time, the real exchange rate increases, giving a boost to international competitiveness and hence reshaping the pattern of specialization. Some firms that were unable to compete with foreign firms with the old RER become competitive with the new one. The diversification of exports follows as firms of the periphery enter new external markets. As a result, expectations over future growth become more optimistic, the animal spirit is reinvigorated and so is investment in the periphery ( $\gamma_{0}$ goes up in the new equilibrium). The income elasticity of exports will be higher than it was before the fall in the monopoly power of the periphery firm (higher $g_{s}^{*}$ ). 
In other words: the effective rate of growth reacts and converge to the new BOPconstrained rate of growth. The short-run decline in growth turns into a higher medium-run equilibrium rate of growth as a result of the easing of the external constraint. At the same time, income distribution improved (the wage share increased because $z$ falls). The short-run depression in the incentives to invest associated with a fall in the profit share is more than compensated by the subsequent rise in investment made possibly by more optimistic expectations regarding future economic growth. This story is compatible with Blecker's observation that an economy may

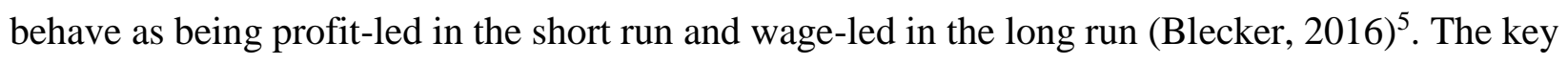
for understanding why the increase in the profit share compromises growth in the long run is its negative impact on the RER and on the Balance-of-Payments-constrained rate of growth.

The RER does not depend exclusively on the profit share. If wages lag behind productivity growth in the periphery, it is possible to have a rise in the profit share in the short run which does not reduce competitiveness in the medium run. In this case a worsening of income distribution may be compatible with both a positive short-run impact on economic growth (in a profit-led economy) and a medium-run rise in the equilibrium growth rate. Such a rise stems from export diversification based on the reduction of unitary wage costs for a given desired mark-up. This case will not be addressed in this paper.

So far we have assumed that the technology gap is given. But in the long run the technology gap may change as a result of domestic efforts at technical change and the international diffusion of technology (see Appendix 2). What happens if the periphery-for instance, by mans of a new industrial and technological policy that reinforces what has been called the "absorptive capabilities of the country, Narula (2002)—reduces the technology gap? The income elasticity of exports increases for any given value of $z^{f}$ and the RER. The isocline $\widehat{\gamma_{0}}=0$ shifts to the right, to ${\widehat{\gamma_{0}}}^{\prime}=$ 0 . The result is a higher rate of growth with the same income distribution, as autonomous expenditures increases from $\gamma_{01}^{e}$ to $\gamma_{02}^{e}$ in equilibrium. This represents the concept of "authentic competitiveness" set forth by Fernando Fajnzylber (1990), which is competitiveness based on technological learning and structural change, not in the depression of real wages. This is an

\footnotetext{
${ }^{5}$ In the case of the RER, Blecker observes that lower wages may provide just a temporary advantages as compared to technological learning, which reshapes comparative advantages in the long run. We acknowledge this temporal dimension by assuming that the effect of a fall in $z$ works in the medium run, while in the long run the driving force of convergence is technological catching up. More on this below.
} 
enduring source of growth as increasing returns that reproduce technological asymmetries in the absence of industrial policy.

An effect similar to that of a fall in the technology gap comes out of a rise in the global demand for periphery goods - such as that represented by the rise of China in the past three decades-, although these positive effects are usually confined to certain periods or cycles in commodity prices (the "commodity lottery"). The shift in global patterns of demand in favor of the periphery, brought about by the Chinese new enhanced role in the international system, raises the equilibrium rate of growth of the periphery for a given degree of export diversification and for a given RER, by easing the external constraint on growth (Pérez Caldentey and Vernengo, 2015; Moreno-Brid and Garry, 2016; ECLAC, 2018). This result may be less straightforward, however, than the reduction of the technology gap by faster technical change in the periphery. If the increase in global demand enhances the monopoly power of the exporting firms in the periphery ( $z^{f}$ increases and $q$ goes down in equilibrium), then the degree of diversification may actually fall and - at least partially — hinder the expansionary stimulus provided by the international markets. Such stimulus will be limited by the loss of international competitiveness in sectors which are not the main beneficiaries of the export boom (as in the Dutch Disease phenomena). Higher growth in global demand, if associated with enhanced power for highly concentrated exporters, may come hand in hand with a higher $z^{f}$ and lower diversification.

\section{The wage-led economy}

Two different scenarios arise in a wage-led economy (in which $\left.\left(\partial\left(g_{s}\right) / \partial z\right)<0\right)$. If the positive effect of a fall in the profit share on domestic demand is lower than its positive effect on export growth, then Figure 1 still adequately represents the adjustment process. The reason is that 
a high level of investment will be required to keep the external sector in equilibrium when competitiveness is high (low $Z^{f}$ ), and hence the $\widehat{\gamma_{0}}=0$ isocline continues to be downward sloping.

Figure 2. Growth, profit shares and competitiveness in the medium run: wage-led in the short run and in the long run

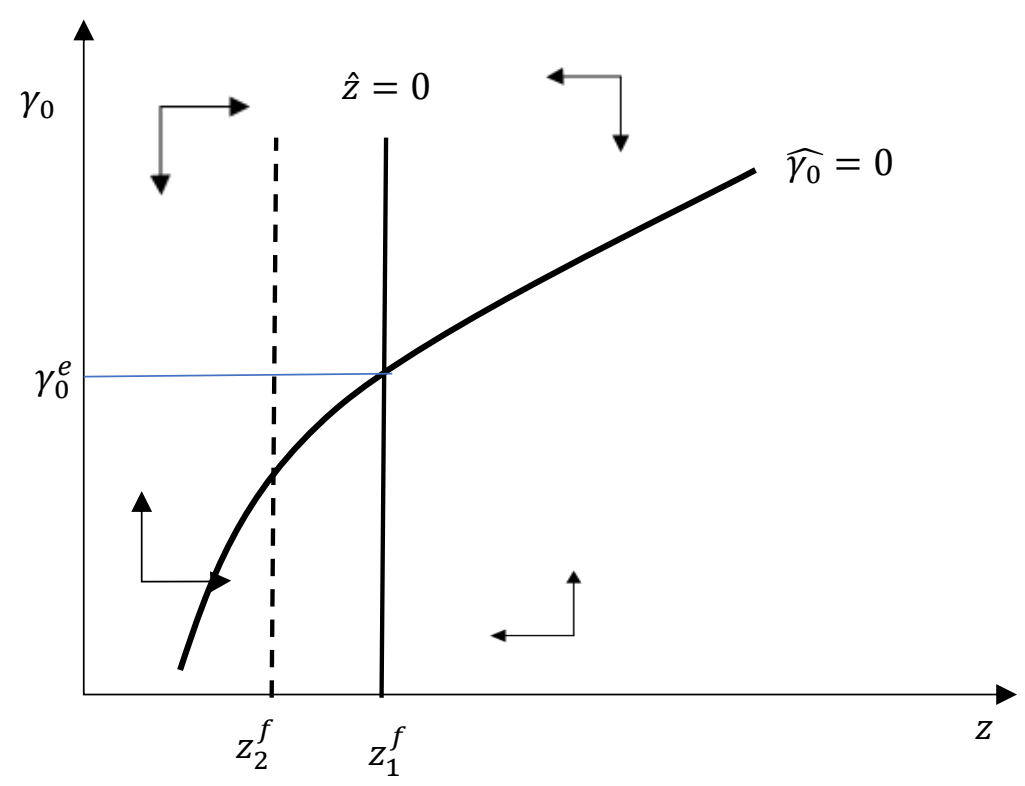

A different scenario emerges when the response of domestic demand to a fall in the profit share is strong enough to overcome the positive increase in competitiveness produced by a lower $Z^{f}$. This is the scenario represented in figure 2. A fall in $Z^{f}$ increases exports, but it has such a strong effect on domestic consumption, that a deficit in the trade balance emerges. Now the $\widehat{\gamma_{0}}=$ 0 isocline has a positive slope. If $z^{f}$ falls, $\gamma_{0}$ must fall too to make more room to the expansion of consumption in total aggregate demand. Such an expansion of workers' consumption is made possible by the increase in competitiveness (and higher $g_{S}^{e}$ ) associated with a lower monopoly power and a higher RER. 


\section{Concluding remarks}

This paper presented a formal version of New Structuralism by including in a BOPconstrained growth model (built in the spirit of the old Structuralism and Thirlwall's Law) three specific assumptions about the process of adjustment between the effective rate of growth and the equilibrium rate of growth. First, changes in expectations about future growth bring about changes in investment decisions, reducing or increasing aggregate demand as a response to a deficit or a surplus in the trade balance. Second, the real exchange rate is defined by wage bargaining and the degree of monopoly in the labor and goods markets under imperfect competition. Third, the RER and relative technological capabilities in center and periphery impact on the degree of diversification and the pattern of specialization, thereby shaping the ratio between the income elasticity of exports and imports.

The model gives support to some of the core policy recommendations associated with the New Structuralist approach to economic development. On the one hand, a policy for building technological capabilities and transforming the pattern of specialization is crucial for long-run growth. Otherwise, the efforts for boosting aggregate demand by means of traditional macroeconomic tools (for instance, an expansive fiscal policy) will be frustrated by the emergence of external disequilibria and an unsustainable debt. On the other hand, a competitive and stable RER is a necessary complement to policies for structural change. An industrial policy coexisting with a highly appreciated domestic currency would be totally ineffectual: all its positive effects on learning and productivity growth would be neutralized by the loss of competitiveness stemming from a low RER.

Rodrik (2008) has argued that in countries with poor institutional capabilities, a high and stable RER can work as a second-best option for industrial policy. However, using the RER as the single instrument to promote competitiveness has strong deficiencies. A high RER implies a lower real wage and therefore carries negative distributive implications (spurious competitiveness). In addition, technological learning shows high degrees of inertia, lock in and hysteresis phenomena There are slow-learning traps that cannot be overcome by market forces alone. Industrial and technological policies should invest and encourage an institutional setting conducive to the interaction of public and private agencies (some profit-oriented, others working under different, non-market rules, as universities or research centers) engaged in innovation and the diffusion of 
technology. A macroeconomic policy concerned with competitiveness is a necessary complement to, but not a substitute for this institutional setting.

\section{Appendix I}

It is interesting to contrast the determinants of investment and growth in the modified Thirlwall-Dutt model and in the original Dutt (2002) model. The critical theoretical question raised by equation (15) is which variables are responsible for leading the economy to its medium-run equilibrium. Dutt (2002) makes the investment rate in the periphery a positive function of the terms of trade, and hence a negative function of the RER. This allows this author to rewrite equation (15) by including $q$ in the argument of the investment function as follows:

$$
\hat{q}=\left[1 /\left(\mu_{S}+\mu_{N}-1\right)\right]\left(\varepsilon_{S} g_{S}(q)-\varepsilon_{N} g_{N}\right) \text {, with }\left(\partial g_{S} / \partial q\right)<0
$$

The equilibrium solution is stable. The dynamics is driven by changes in the terms of trade, which in the model are the inverse of the RER. Assume that initially the RER is below equilibrium and $g_{S}$ above the equilibrium rate of growth, and hence $\varepsilon_{N} g_{N}<\varepsilon_{S} g_{S}(q)$. The periphery is experiencing a trade deficit. RER will be increasing $(\hat{q}>0)$ and $g_{S}$ will be falling along with the terms of trade to balance the external sector.

In the modified model we suggested in the article, the forces at work are different. Assume for simplicity that the RER is always in equilibrium (i.e., capitalists almost instantaneously set $z=$ $z^{f}$ ). The dynamics of the modified Thirlwall-Dutt model boils down to:

$$
\widehat{\gamma_{0}}=\varphi\left\{\varepsilon_{N(q, G)} g_{N}-\varepsilon_{S}\left[g_{S}\left(\gamma_{0}\right)\right]\right\}
$$

Changes in growth relies entirely on changes in the animal spirit. Nevertheless, the RER

does play a role in the adjustment process: the higher the RER in equilibrium (the lower $z^{f}$ ), the more diversified the economy, and the higher the rate of investment in equilibrium.

Using equation (21) (or the dynamic system in the state variables $\gamma_{0}$ and $z$ presented above) instead of equation 20 has some advantages. First, the empirical evidence we reviewed in section 
2 suggests that a higher RER in the long run tends to be related to a higher rate of economic growth and more rapid structural change. In equation (20), a lower RER boosts growth, while in equation (21) it has the opposite effect. Second, the idea that the adjustment takes place by changes in aggregate demand rather by changes in prices is one of the key tenets of Thirlwall's Law — and of the Structuralist tradition for that matter (Pérez Caldentey, 2015). Last but not least, in many periphery countries the RER is the focal point of the bargaining process between workers and capitalists (Frenkel and Rapetti, 2011). A rise in the real exchange rate have impacts on real wages and income distribution and triggers the distributive conflict. This implies that the RER does not respond exclusively to what is going on in the external sector as in Dutt (2002), but is part and parcel of the bargaining process in the labor market and in the goods market (through mark-up pricing). Equation (20) cannot be easily reconciled with the Kaleckian model of inflation based on the distributive conflict.

\section{Appendix 2: The long run and the technology gap}

In the long run relative technological capabilities evolve as a result of different rates of innovation in the center and diffusion of technology in the international economy. The technology gap will vary up to the point in which the rate of innovation in the center equals the rate of diffusion of technology to the periphery (implying a stable technology gap).

To analyze the evolution of the technology gap $\left(G=T^{C} / T^{P}\right)$ it is necessary firstly to define the forces that drive $T^{C}$ (technological capabilities in the center) and $T^{P}$ (technological capabilities in the periphery). The growth rate of the stock of knowledge in the North is exogenous, $\hat{T}^{C}=r$. The growth rate of the stock of knowledge in the South $\left(\widehat{T}^{P}\right)$ depends on two factors: (i) potential knowledge spillovers from the center; (ii) investments in the South to transform this potential into effective capabilities (Verspagen, 1993). Potential spillovers (factor i) from the center increase with the technology gap $G$ : the higher is $G$, the higher the opportunity for the periphery to learn from / imitate / improve on innovations that already exist in the center. $G$ represents a stock of knowledge the periphery could tap into if it makes the necessary investments (factor ii). These investments strengthen the National System of Innovation, namely the set of institutions, firms and 
agencies that encourage innovations and enhance the diffusion of foreign technology in the laggard economy (Narula, 2002; Fagerberg et al, 2009).

The relationship between technological spillovers and the technology gap is nonlinearas, suggested by Verspagen (1993). If $G$ is low, an increase in the technology gap increases international technological spillovers from center to periphery; after some critical value of $G$, however, technological spillovers slow down because the gap becomes too large, making it more difficult for the laggard economy to absorb foreign technology. Formally:

$$
\widehat{T}^{P}=G(h-j G)
$$

Therefore, the rate of growth of the technology gap is given by:

$$
\widehat{G}=\widehat{T}^{C}-\widehat{T}^{P}=r-G(h-j G)
$$

The parameter $r$ gives the rate of growth of innovation in the center, $h$ reflects increasing returns to innovation in the center, while $j$ represents efforts at catching up in the periphery (a very crude proxy of the NSI). There are two equilibrium values for $G$ (which make $\widehat{G}=0$ ), of which only $G_{0}^{e}$ is stable (see figure 3). Maximum spillovers are obtained when $G=h / j \rightarrow \widehat{T}^{P} \max$.

The higher the technological efforts in the periphery, the lower the technology gap in equilibrium. Figure 3 shows the effect of a rise in $j$ due to the strengthening of the technological policy in the periphery, from $j_{0}$ to $j_{1}$. In equilibrium the technology gap falls from $G_{0}^{e}$ to $G_{1}^{e}$. 
Figure 3: Strengthening the NSI in the periphery

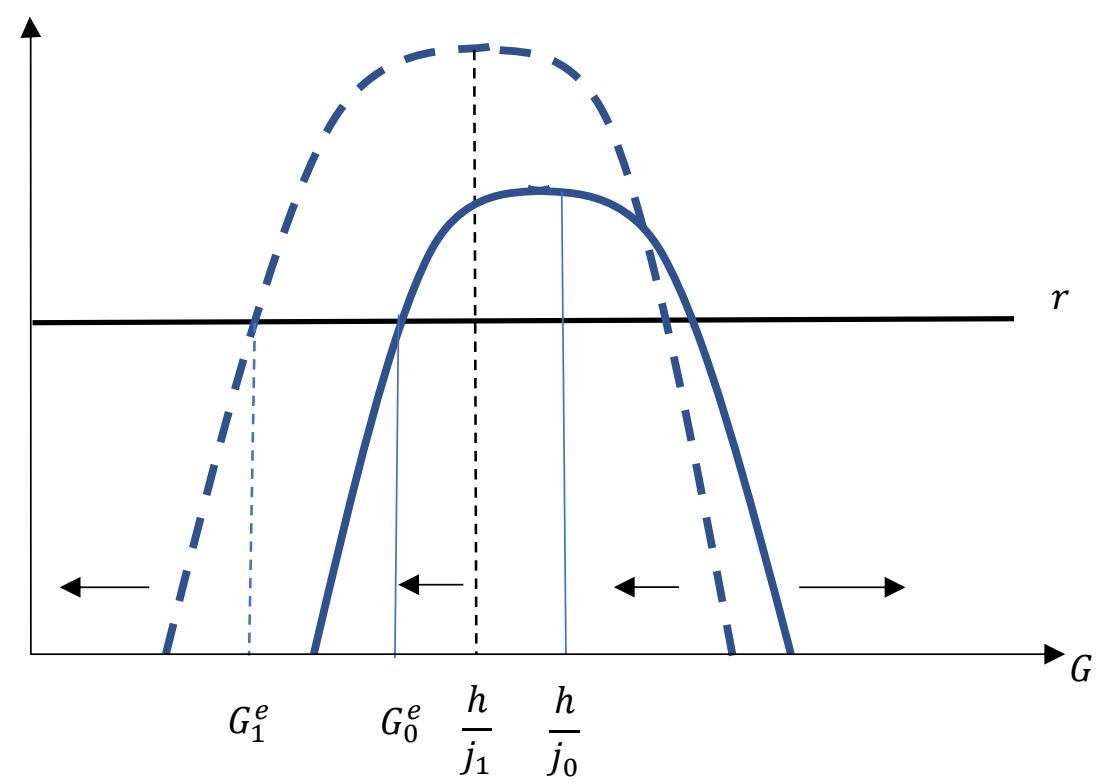

The take away from this simple model of catching up / falling behind in technology is:

a) Foreign technology can be used to build up indigenous capabilities, but this becomes more difficult when the technology gap is too large (and impossible if the initial value of the technology gap is so high that it will increase without bounds);

b) The NSI (captured by $j$ ) enhances learning and diffusion of foreign technology across all periphery firms, reducing the technology gap;

c) The lower the technology gap, the higher the degree of export diversification and the higher the Balance-of-Payments-constrained rate of growth 


\section{References}

Agosin, M. R., Alvarez, R., and Bravo-Ortega, C. (2012), 'Determinants of export diversification around the world: 1962-2000’, The World Economy, 35(3), 295-315.

Araujo, R. A., and Lima, G. T. (2007), 'A structural economic dynamics approach to balance-ofpayments-constrained growth’, Cambridge Journal of Economics, 31(5), 755-774.

Baldwin, R., (1988), 'Hysteresis in Import Prices: The Beachhead Effect', American Economic Review, Z, 773-785.

Bhaduri, A., and Marglin, S. (1990), 'Unemployment and the real wage: the economic basis for contesting political ideologies’, Cambridge journal of Economics, 14(4), 375-393.

Blecker, R. A. (2011), 'Open economy models of distribution and growth', A modern guide to Keynesian macroeconomics and economic policies, Cheltenham: Edward Elgar, pp. 215-39.

Blecker, R.A. (2016) "Wage-led versus profit-led demand regimes: the long and the short of it", Review of Keynesian Economics, 2016, vol. 4, issue 4, 373-390.

Bogliacino, F. and Pianta, M. 2016., 'The Pavitt Taxonomy, revisited: patterns of innovation in manufacturing and services', Economia Politica, 33, 153-180. Available at: https://doi.org/10.1007/s40888-016-0035-1

Bresser-Pereira, L. C., (2016), 'Reflecting on new developmentalism and classical developmentalism', Review of Keynesian Economics, 4(3), 331-352, available at: https://doi.org/10.4337/roke.2016.03.07

Bresser-Pereira, L. C., Oreiro, J. L. and Marconi, N. (2014), 'Developmental Macroeconomics', London: Routledge.

Caglayan, M., \& Demir, F. (2019), 'Exchange rate movements, export sophistication and direction of trade: the development channel and North-South trade flows', Cambridge Journal of Economics, available at: https://doi.org/10.1093/cje/bez005.

Carlin, W., \& Soskice, D. (2005), 'Macroeconomics: imperfections, institutions, and policies', Oxford: OUP Catalogue.

CEPAL, N. (2018), 'Desarrollo e igualdad: el pensamiento de la CEPAL en su séptimo decenio', Textos seleccionados del período 2008-2018.

Cimoli, M. and J. Katz (2003), 'Structural Reforms, Technological Gaps and Economic Development: A Latin American Perspective', Industrial and Corporate Change, 12 (2), April, 387-411. 
Cimoli, M., Fleitas S. and Porcile, G. (2013), 'Technological intensity of the export structure and the real exchange rate', Economics of Innovation and New Technology, 22(4), 353-372, available at: DOI: 10.1080/10438599.2012.748504

Cimoli, Mario \& Pereima, João Basilio \& Porcile, Gabriel (2019) "A technology gap interpretation of growth paths in Asia and Latin America," Research Policy, vol. 48(1), pages 125-136.

Colacelli , M . (2010), 'Intensive and Extensive Margins of Exports and Real Exchange Rates', Barnard College, Columbia University, mimeo

Diao, X., McMillan, M., and Rodrik, D. (2017), 'The recent growth boom in developing economies: A structural change perspective', (No. w23132). National Bureau of Economic Research.

Dixon, R., and Thirlwall, A. P. (1975), 'A model of regional growth-rate differences on Kaldorian lines’, Oxford Economic Papers, 27(2), 201-214.

Dutt, A. K. (2002), 'Thirlwall's law and uneven development', Journal of Post Keynesian Economics, 24(3), 367-390.

Elbadawi, I. A., Kaltani, L., \& Soto, R. (2012), 'Aid, real exchange rate misalignment, and economic growth in Sub-Saharan Africa', World Development, 40(4), 681-700.

Faberberg, J. Srholec, M. and Verspagen, B. (2001), 'Innovation and Development', in Hall, B. and Rosenberg, N. (eds.): Handbook of the Economics of Innovation, Amsterdam: North Holland.

Faberberg, J. and Verspagen, B. (2002), 'Technology gap, Innovation-Diffussion and Transformation: An Evolutionary Interpretation', Research Policy, 31, 1291-1304.

Fajnzylber, Fernando (1990), 'Industrialization in Latin America: From the "black box" to the empty box', Cuadernos de la Cepal No. 60, August 1990.

Felipe, J., Abdon, A. and Bacate, M. (2012), 'Product Complexity and Economic Development', (with Arnelyn Abdon, Marife Bacate, and Utsav Kumar). Structural Change and Economic Dynamics, 23(1), 36-68.

Ffrench-Davis, R. (2012), 'Employment and real macroeconomic stability: The regressive role of financial flows in Latin America', International Labour Review, International Labour Organization, vol. 151(1-2), 21-41, 06.

Ffrench-Davis, R. and Ocampo (2001), 'The globalization of financial volatility', in R. Ffrench-Davis (ed.), Financial Crises in 'Successful' Emerging Economies, Washington, DC: Brookings Institution Press/ECLAC. 
Frenkel, R. and Rapetti, M. (2011), 'A Concise History of Exchange Rate Regimes in Latin America', in Ocampo, J.A. and Ros, J. (2011) The Oxford Handbook of Latin American Economics, Oxford: Oxford University Press.

Freund, C., and Pierola, M. D. (2012), 'Export Surges: The Power of a Competitive Currency', Journal of Development Economics, 97(2), 387-395.

Freund, C., and Pierola, M. D. (2008), 'Export Entrepreneurs: Evidence from Peru.', World Bank Policy Research Working Paper 5407.

Gala, P. (2008), 'Real exchange rate levels and economic development: theoretical analysis and econometric evidence', Cambridge Journal of Economics, 32(3), 273 - 288.

Gouvêa, R. R., and Lima, G. T. (2010), 'Structural change, balance-of-payments constraint, and economic growth: evidence from the multisectoral Thirlwall's law', Journal of Post Keynesian Economics, 33(1), 169-204.

Goya, D. (2014), 'The Multiple Impacts of the Exchange Rate on Export Diversification', Cambridge Working Paper in Economics, available at: https://doi.org/10.17863/CAM.5841

Goya, D . (2018), 'The Exchange Rate and Export Variety: A Cross-Country Analysis With Long Panel Estimators', Working Papers no. 2018-01, Escuela de Negocios y Economía, Pontificia Universidad Católica de Valparaíso

Guzmán, M., Ocampo, J.A. and Stiglitz, J. (2018), 'Real Exchange Rate Policies for Economic Development', World Development, 110: 51-62.

Libman, E., Montecino, J.A., Razmi, A., (2019), 'Sustained investment surges', Oxford Economic Papers, gpy071, available at: https://doi.org/10.1093/oep/gpy071

Lima, G. T., and Porcile, G. (2013), 'Economic growth and income distribution with heterogeneous preferences on the real exchange rate', Journal of Post Keynesian Economics, $35(4), 651-674$.

Marconi, N., Araújo, E. C. and Oreiro, J. L. (2015), 'The exchange rate, income elasticities, and structural change: theoretical foundations and empirical evidence', paper presented at $43^{\circ}$ Encontro Nacional de Economia da Anpec, Florianópolis, Brasil.

Mbaye, S. (2013), 'Currency undervaluation and growth: Is there a productivity channel?', International Economics, 133, 8-28.

McMillan, M. S., and Rodrik, D. (2011), 'Globalization, structural change and productivity growth', (No. w17143). National Bureau of Economic Research. 
Mesquita Moreira, M., Pierola, M. D., and Sánchez-Navarro, D. (2017), 'Exchange Rate Devaluation and Import Substitution in Latin America and the Caribbean', Inter-American Development Bank.

Missio, F. J., Jayme Jr, F. G., Britto, G., and Luis Oreiro, J. (2015), 'Real Exchange rate and economic growth: new empirical evidence', Metroeconomica, 66(4), 686-714.

Moreno-Brid, J. C., and Garry, S., (2016), 'Economic performance in Latin America in the 2000s: recession, recovery, and resilience?' Oxford Development Studies, vol. 44(4), 384-400.

Narula, R. (2004), 'Understanding Absorptive Capacities in an Innovation Systems Context: Consequences for Economic and Employment Growth', DRUID Working Paper n. 04-02, December.

Nassif, A., Feijó, C. and Bresser-Pereira, L.C. (2018), 'The case for reindustrialization in developing countries: toward the connection between the macroeconomic regime and industrial policy in Brazil', Cambridge Journal of Economics, 42(2), 355-381, available at: https://doi.org/10.1093/cje/bex028.

Nassif, A., Feijó, C., and Araújo, E. (2015), 'Structural change and economic development: is Brazil catching up or falling behind?', Cambridge Journal of Economics, 39(5), 1307-1332, available at: https://doi.org/10.1093/cje/beu052

Neto, A. S. M., and Porcile, G. (2017), 'Destabilizing austerity: Fiscal policy in a BOPdominated macrodynamics', Structural Change and Economic Dynamics, 43, 39-50.

Ocampo, J.A., Rada, C and Taylor, L. (2009), 'Growth and Policy in Developing Countries: A Structuralist Approach', Oxford: Oxford University Press.

Otani, A., Shiratsuka, S., and Shirota, T. (2003), 'The decline in the exchange rate pass-through: evidence from Japanese import prices', Institute for Monetary and Economic Studies, Bank of Japan.

Otani, A., Shiratsuka, S., and Shirota, T. (2006), 'Revisiting the decline in the exchange rate pass-through: further evidence from Japan's import prices', Monetary and Economic studies, 24(1), 61-75.

Pérez Caldentey, E. (2015), 'Una lectura crítica de“la lectura crítica”de la Ley de Thirlwall,'Investigación Económica, LXXIV(292), 47-65.

Pérez Caldentey, E., and Vernengo, M., (2015), 'Towards an understanding of crisis episodes in Latin America: a post-Keynesian approach', Review of Keynesian Economics, 3(2), 158-180.

Razmi, A., Rapetti, M., and Skott, P. (2012), 'The real exchange rate and economic development', Structural Change and Economic Dynamics, 23, 151-69. 
Robinson, J. (1966), 'The New Mercantilism, An Inaugural Lecture', Cambridge: Cambridge University Press, 1966. In J. Robinson, Collected Economic Papers, Volume four, Oxford: Basil Blackwell, 1973, 1-13.

Rodríguez, O. (2006), 'El estructuralismo latinoamericano’, Ciudad de México: Siglo XXI.

Rodrik, D. (2008), 'The real exchange rate and economic growth', Brookings papers on economic activity, 2008(2), 365-412.

Verspagen, B. (1993), 'Uneven Growth between Interdependent Economies: An Evolutionary View of Technology Gaps', Trade and Growth. Avebury, Ashgate Publisher. 